\title{
EDITORIAL
}

\section{Libertad de enseñanza, voluntad de diálogo y compromiso}

Presentamos a nuestros lectores este nummero monográfico so* bre wlos problemas cruciales de la enseñanza en Fspaña" Nos refermos en él a codos los niveles educativos a excepción del uni versitario. Comenzamos por desplegar un panorama estadistico en tomo a la población escolar (J. Tena Artigas), abordamos la pro. blemática de la escolarización (F. Diez Burgos), mos interesamos por el terna de la callad (1. Gutiérrez Ruiz) y por el de la sulduacion y organización protesional del profesorado (J. L. Negro Fernández y M. D. Conzález Barón). La segunda parte, "Política educativan, y tambien en buen grado la tercera, uVentana al exterior", uatan una serie de cuestiones que surgen, on el tondo, desde una raiz comin: la de la llocrad de enseñanza con lodas sus consecuena

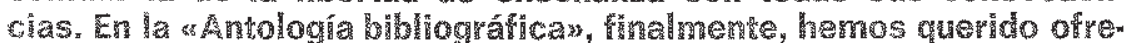
cer cierta zrepresentación a todos los colores de la gama ideoló. gica sobre la temática.

Pero, hecha esta mu breve presentación, mueremos dedicar esas Ineas editorales a una ldea: la del pacto escolar, la del dín logo, la del compromiso.

* la verdad es que quistéramos sinceranente poder habhar de

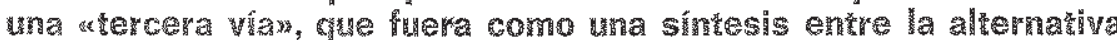

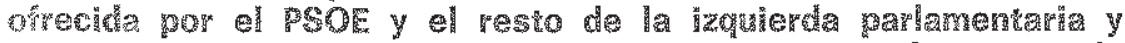

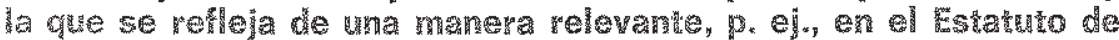
Centros Escolames, recientemente aprobado por el Congreso, y en

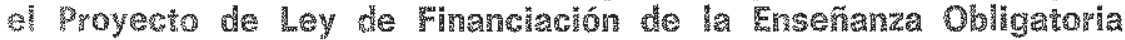

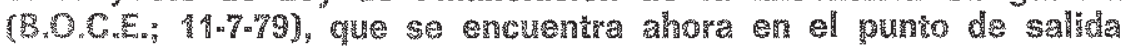

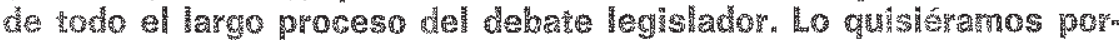

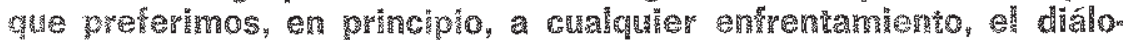

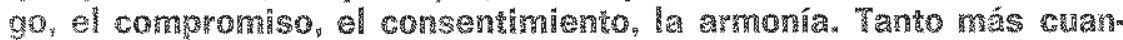

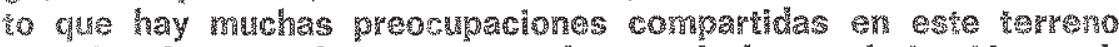
pow Gobierno y la oposichón: el wam do la escolarización total, el de la reconvera remuneración del protesorado, etc.

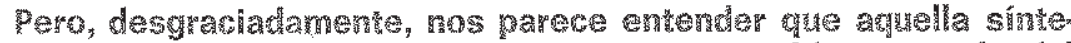

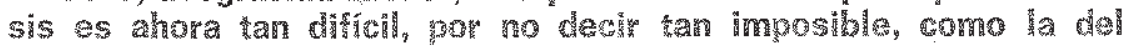

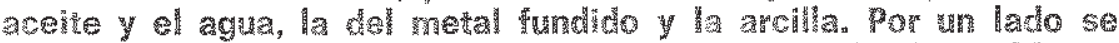

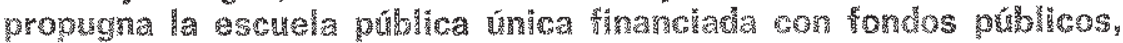

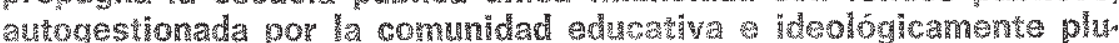
ralis 


\section{EDITORIAL}

centros financieramente apoyada por el Estado, la participación in. terna de la comunidad educativa sin que tenga que llegar a la autogestión empresarial, el phuralismo ideológico de centros pero no de necesidad el pluralismo ideológico dentro de cada centro.

De hecho, el precario consenso logrado a la hora de redactar el artículo 27, sobre la enseñanza, de nuestra Constitución, ha quedado hecho pedazos en el momento de tramitar algunas de estas leyes que lo concretan de una manera más precisa. Ciertamente no nos consideramos nosotros aqquí capaces de ofrecer icieas vâ" lidas para recomponerto del todo. Pero, sin embargo y a pesar de que nos alineemos claramente en la vía de la libertad de inviciativa con todas sus consecuencias financieras para el Estado y en el camino del pluralismo de centros, quisiéramos también proclamar aquí con todas nuestras fuerzas: no se manipulen las buenas ideas de la libertad de ensenanza; no se haga simplemente poltica conservadora de próección solapada de intereses egóstas apoyándo. se en los más nobles coneeptos de democracia, libertad, derechos de los padres, etc, o en las declaraciones más solemnes de los organismos internacionales.

Porque si hablamos de libertades democráticas, la democracia es, ante todo, la práctica y el ejercicio del diálogo y el compronüso. Es verdad que formalmente podemos definir la democracia como el acuerdo en un procedimiento para la toma de decisiones por mayoria; que también es cierto que la mayoría, mientras lo sea está en condiciones de ir simplemente imponiendo sus decisiones de una manera mecánica. Pero siempre y a pesar de todo, la voluntad de diálogo y de compromiso debería estar presente, a nuestro jucicio, en la práctica de la democracia, aunque no sea por otro motivo que por éste; cuanto más amplitud de adhesiones obtenga cualquier proyecto para la comundad poliucica, ésta irá ganando tan to más en artaigo y en estabilidad. Vy esto últumo a codos nos inte. resa.

Pues bien; en la materia oue nos alañe, pensamos que la fidelidad y lealtad sinceras al principio de libertad de enseñanza con todas sus secuelas obliga, si no se quiere sencillamente serwirse te el manipulandolo, a lo siguiente:

- A intentar alcanzarr, en los plazos más breves posibles de thempo, altes cotas de participación interna por parte de la comunidad educativa en los centros no estatales de ensenanza. ¿No se ha estado diciendo, frente a las demandas alternativas de autogeslion, gue la participación interna de los padres, de los profesores, de los alumnos sí que se admitha, incluso en niveles relativamente próximos a la autogestión? Encluso en niveles formal y libremente autogestionarios?

- A no privilegiar en los centros no estatales a las clases acomodadas: a tener, por el contrario, las puertas ablertas a todos; más aun, a dar priontdad a los más humildes, a los más pobres, a los más débiles econónicamente. Cuando se tacha de discrimina.

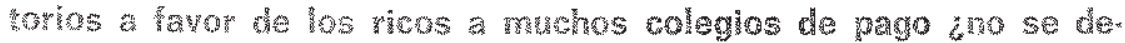


fienden éstos diciendo que la falta de libertad subvencionada obliga a ser, de esta manera, "clasistas"? Si nuestra sociedad, pues, entra en el futuro, por esa libertad, ya no tendrán excusa.

- A colaborar con el Estado en la escolarización total, abriendo nuevas aulas preferentemente alli donde existan más niños $\sin$ escuela. Se colaboraría, de esta manera, a romper la disyuntiva entre prioridades: "primero es la escolarización total", dice la izquierda" rlas subvenciones deben ir paralelas al proceso de extensión de la escolaridad", sostienen el centro y la derecha.

- A ser flexibles y democráticos en materha de idearios; el de recho a un ideario no es una patente de corso para la dictadura ideom lógica ní para la ruptura de toda metodiología de dílogo y compro miso. A acentuar la máxima flexibilidad del ideario, por puro respeto a los alumnos, en aquellas zonas, p. ein rurales, en que féc. ticamente y al no existir varios centros, tampoco se da la libertad de elección entre centros diferentes por parte de los padres de los alumnos.

- A ser exigentes y a someterse congrtamente al control pún blico en materia de calidad de la enseñanza. Si se implanta la gratuidad y se admitiere por un centro la financiación estatal de la misma es obligado automáticamente algún control, por parte de los poderes públicos que la otorguen, de la calidad del servicio educativo que se presta.

- A establecer efectivamente, cuando se dieren las condiciones financieras para ello, la total gratuidad. Las actividades complementarias deberían tener siempre carácter voluntario: deberín ser, en su conifunto y por su volumen, residuales y no dar nunca ocasión a discriminaciones.

- Ala solidaridad con los centros estatales en rodos los terrenos y problemas, particularmente en el estuerzo común por el logro de la calidad.

Hubo épocas en que la Iglesia frue la gran educadora de Europa, a través en concreto de las Universidades y de las escuelas de los monasterios. En tiempos más modemos la lglesia se opuso a las nuevas ldeas liberales; recuérdese, $p_{\text {. }}$. en el siglo XX la encí clica Mirari Vos o el Syllabus Errorum de Pio IX. El liberalismo y la llustración declararon entonces la guerra a la Iglesia como sren trógradan en su concepto, y frue d de la escula uno de los prino cipales campos de batalla. Queria ol liberalismo en consecueneia la escuela estatall más por laica y por uneutran gue por estatal. Y la queria de una manera un tanto contradictoria con st propia ldeo. logía, ya que en general defendía el liberalismo una minimización del intervencionismo del Estado en todas las esteras de la vida. Pero lo importante era guitar a la Iglesia ol instrumento de la es" cuela y ello bien valia-pensaban-wura cierta contradicción ideológica. De paso, al propugnar asi la escuela estatal, se llevaban por delante el derecho a la promoción y mantenimiento de escuelas no sólo de la fylesia, suno de cualcherer otra entidad privada.

Los socialistas historicos, deronsones de Ya socallzacion, de 


\section{EDTORIAL}

la estatalización, del máximo intervencionismo del Estado, coinci dieron en este tema de la escuela sorprendentemente con sus an tagonistas ideológicos, los liberales. V también ellos pensaban no sólo en la escuela estaval sino en la escuela unewtra" y laica, para poder romper el muro que la lglesia oficial historica, que anatematizó el socialismo, estaba popniendo al avance de cstas nuevas ideas.

Pero hoy debemos abandomar, nos parece, las inercias del par sado. Hoy el Concipio Vaticano II ha asumido en gran medida, como espacio de realización de la dignidad humana, el modelo de sociedad propio de las democracias occidentales, que son un producto de raices Hberales, aungue con imjertos intervenclonistas. V en cuanto al socialismo, la lglesia admite hoy, como alsernatiza socio política valida, en principio, todo socialismo, menos el socialsmo totallario. Léase, p. el. a este respecto, la carta wOtogesima Ad ventens", de pablo $\mathrm{V}$, escrib con ocasion de cumplyse el ochenta

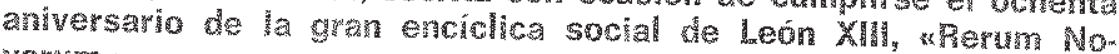
varum".

Por eso nos parece mucho más suxin y acerrada que la de orros socialismos, la postura del socialismo holandés qua vio ya desde primeros de siglo (léase en este numero el articulo de H. Brigmans) que el camino de las mayorias tavorables a su modelo de sociedar se encontraba nus an woto de las masas creyentes, no inganem tandolas en ol punto de la libertad de enseñanza y de la escuela "neura", que en hacer causa combn en el tema ascolar con $\$$ iss antagonistas políticos, los liberales. Cuanto más úgica será esta postura hoy on que, como decimos la iglesia oficial acepta como

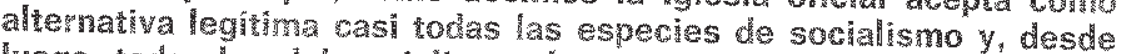
Hego, todas las del socialismo democrátco; hoy entute los parth dos social'stas curopeos se wutren en buena parte de los votos de los cristianos; hoy en que exhan an la lolesia grupos y comu nidades cuallicados que pionsan tever razones desde sil fe para

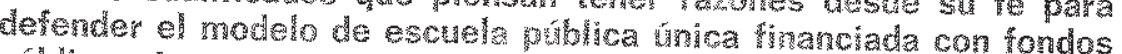

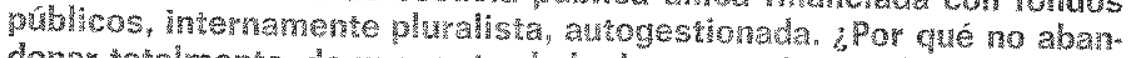
donar rotamente, de no y otro lado, los sectarismos de la vistoria?

Tal seria, a hestro jucho, la condichón de un nuevo dialogo de un nevo compromiso.

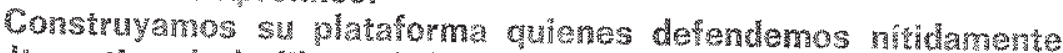

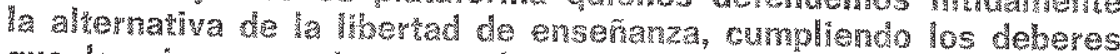
que la misma nos lmpone, alghnos de los cuales-imponantas-

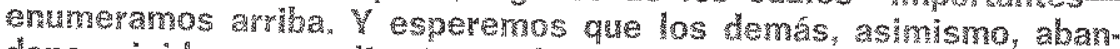
donen rigideces, totalltarismos tomales ineológicos y las religutas de hodo sertarismo. Ahondemos eme todos las raines del consen

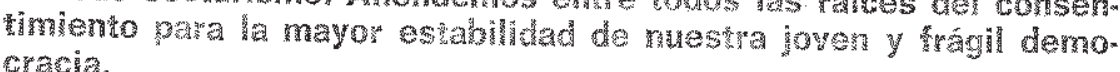
cracina 